\title{
Parameters Optimization for Friction Spot Welding of AZ31 Magnesium Alloy by Taguchi Method
}

\section{(Otimização dos Parâmetros de Soldagem por Fricção por Ponto da Liga de Magnésio AZ31 pelo Método de Taguchi)}

\author{
Leonardo Contri Campanelli ${ }^{1}$, Uceu Fuad Hasan Suhuddin ${ }^{2}$, Jorge Fernandez dos Santos ${ }^{2}$, Nelson Guedes de Alcântara ${ }^{1}$ \\ ${ }^{1}$ Federal University of Sao Carlos (UFSCar), Department of Materials Engineering (DEMa), Sao Carlos, Sao Paulo, Brazil- \\ leoccampa@hotmail.com,nelsong@ufscar.br \\ ${ }^{2}$ Helmholtz-Zentrum Geesthacht GmbH, Institute of Materials Research, Materials Mechanics, Solid State Joining Processes (WMP), \\ Geesthacht, Germany-uceu.suhuddin@hzg.de,jorge.dos.santos@hzg.de
}

\begin{abstract}
Friction spot welding (FSpW) is a solid state welding process suitable for producing spot-like joints, especially in lightweight materials, which are particularly interesting due to the weight saving potential. The plunging of an especially designed non-consumable and rotating tool creates a connection between overlapped sheets through frictional heat and plastic deformation. Minimum material loss is observed, and therefore a fully consolidated joint with flat surface (no keyhole) is obtained. In the current study, the effect of FSpW parameters, such as rotational speed, plunge depth and dwell time, on lap shear strength of AZ31 magnesium alloy joints was investigated. The optimization of input process parameters was carried out through Taguchi approach of DOE. Analysis of variance was applied to determine the individual importance of each parameter. Main effect plots were used to indicate the best levels for maximizing lap shear strength. The results show that tool plunge depth has the higher effect on the weld strength, followed by rotational speed and dwell time.
\end{abstract}

Key-words: Friction spot welding; AZ31 magnesium alloy; Taguchi method.

Resumo: A soldagem por fricção por ponto (FSpW) é um processo de soldagem no estado sólido adequado para a produção de juntas pontuais, especialmente em materiais leves, que são particularmente interessantes devido ao potencial de redução de peso. A penetração de uma ferramenta não-consumível e rotacional especialmente desenvolvida cria uma junção entre as placas sobrepostas através de calor por fricção e deformação plástica. A perda de material é mínima, obtendo-se, portanto, uma junta totalmente consolidada com superfície plana (sem furo). Neste trabalho, investigou-se o efeito dos parâmetros do FSpW, tais como velocidade de rotação, profundidade de penetração e tempo de residência, na resistência ao cisalhamento das juntas de liga de magnésio AZ31. A otimização dos parâmetros de entrada do processo foi realizada através do método de Taguchi de DOE. A análise de variância foi aplicada para determinar a importância individual de cada parâmetro. Os gráficos dos efeitos principais foram utilizados para indicar os melhores níveis que maximizam a resistência ao cisalhamento. Os resultados mostram que a profundidade de penetração da ferramenta possui a maior influência sobre a resistência da solda, seguida da velocidade de rotação e tempo de residência.

Palavras-chave: Soldagem por fricção por ponto; Liga de magnésio AZ31; Método de Taguchi.

\section{Introduction}

Friction spot welding (FSpW) is a spot solid state technology developed and patented by GKSS Forschungszentrum (now Helmholtz-Zentrum Geesthacht), Germany [1]. A three-part tool comprising pin, sleeve and clamping ring is used to join two or more similar/dissimilar sheets of lightweight materials in lap configuration, such as aluminum (Al) and magnesium (Mg) alloys. The conception of the process aims to eliminate some disadvantages usually observed in other spot-like joining technologies, such as weight penalty, difficulty of automation,

(Recebido em 29/02/2012; Texto final em 01/03/2012).

Artigo originalmente publicado no CONSOLDA 2011 requirement for sealants and corrosion problems in mechanical fastening [2], and the presence of a keyhole after the process in friction stir spot welding (FSSW).

Depending on the plunging component, the process can be divided in two variants with four steps: pin plunge and sleeve plunge [2]. Clamping ring initially fixes the sheets against a backing plate while pin and sleeve begin to rotate in the same direction on the upper surface (Figure 1a). Rotating pin and sleeve are moved in opposite direction to each other (one is plunged into the material while the other moves upwards), creating a cavity where the plasticized material through frictional heat is accommodated (Figure 1b). After reaching the pre-set plunge depth, pin and sleeve retract back to the surface of the plate forcing the displaced material to completely refill the keyhole (Figure 1c). Finally, tool rotation is stopped and tool is withdrawn from the joint leaving a flat surface with minimum material loss (Figure 1d). 


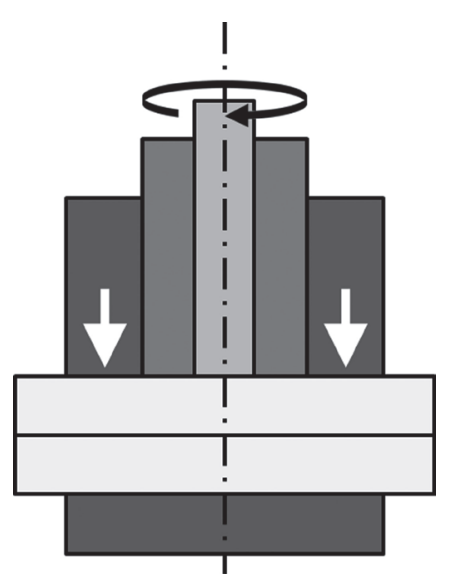

(a)

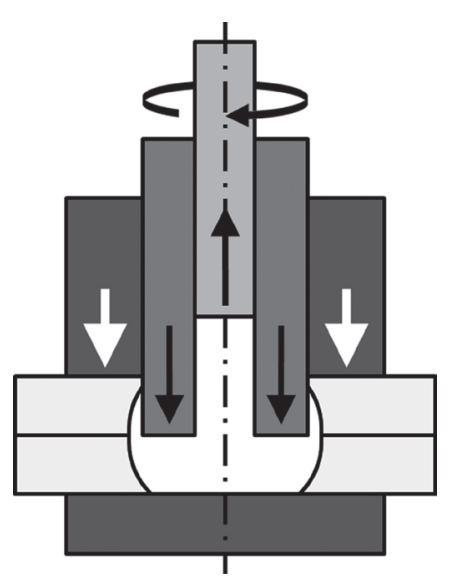

(b)

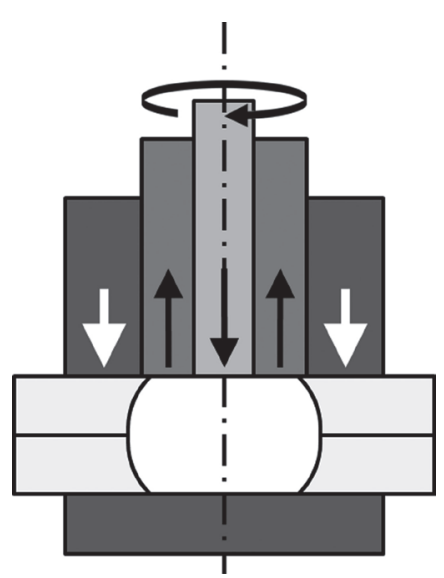

(c)

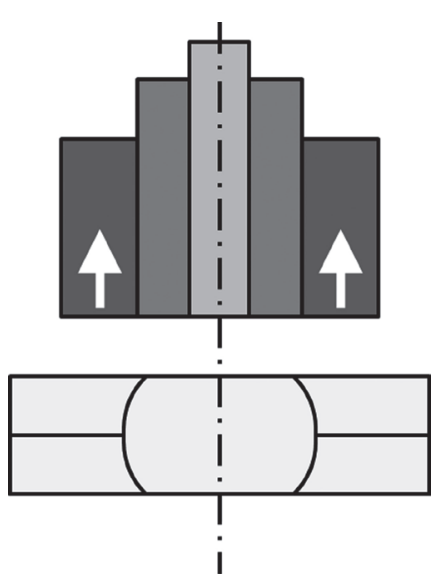

(d)

Figure 1. Illustration of sleeve plunge steps: (a) clamping and tool rotation, (b) sleeve plunge and pin retraction, (c) tool back to surface level and (d) tool removal.

The mechanical performance of a FSpW connection is mainly dependent on the process parameters such as rotational speed (RS), plunge depth (PD) and dwell time (DT). Taguchi technique of Design of Experiments (DOE) has been widely applied to optimize the quality and reliability of materials manufacturing through the optimization of the input process parameters without increasing the experiment time and cost [3]. With a special design of orthogonal arrays, Taguchi provides the optimum settings of parameters, which are insensitive to the variation in environmental condition and other noise effects [4]. Three categories of quality characteristics are defined in the analysis of Signal/Noise $(\mathrm{S} / \mathrm{N})$ ratio: lower-the-better, larger-the-better and nominal-the-best. The $\mathrm{S} / \mathrm{N}$ ratio for each process parameter is calculated based on $\mathrm{S} / \mathrm{N}$ analysis function. A larger $\mathrm{S} / \mathrm{N}$ ratio is normally consistent with better quality characteristics regardless of the category. The level of larger S/N ratio is the optimal process parameter one. Analysis of variance (ANOVA) is performed to investigate which parameters have a significant effect on the quality characteristic $[5,6]$.

Several successful applications of Taguchi method have been reported in the optimization of solid state welding parameters. Lakshminarayanan et al. [6] revealed that tool RS has the major effect on the tensile strength (TS) of RDE-40 Al alloy friction stir welds, followed by welding speed and axial force. An optimum TS of $303 \mathrm{MPa}$ was predicted. Working with FSW on A319 Al alloy, Jayaraman et al. [7] also presented the RS as the dominant parameter, and TS of the optimum combination of parameters was found to be $147 \mathrm{MPa}$. In both studies, the predicted values of TS were in a reasonable agreement with experiment values. Regarding friction based spot welding technologies, few research works using Taguchi method can be found in the literature. Hunt et al. [8] studied the effect of Swing-FSW (alternative spot welding based on FSW) parameters on A6022-T4 Al alloy and showed that hold time increases lap shear strength (LSS). Taguchi approach was also used by Bilici et al. [9] to examine the effect of FSSW parameters on high density polyethylene. DT was found to have the major effect on LSS, followed by tool RS and PD. The predicted value of LSS at the optimum levels was similar to the experimental one.
In this study, Taguchi method is applied to investigate the influence of each FSpW parameter on LSS of AZ31 Mg alloy joints and evaluate the combination of parameters that leads to the highest weld strength.

\section{Materials and Methods}

AZ31B-H24 Mg alloy sheets of $2 \mathrm{~mm}$ of thickness were used in this investigation. FSpW sleeve plunge variant was used to produce the welded specimens in lap-shear configuration with $46 \mathrm{~mm}$ overlap according to ISO 14273:2000 standard. The tool system consisted of a clamping ring, $9 \mathrm{~mm}$ diameter sleeve and $6 \mathrm{~mm}$ diameter pin. Three main process parameters have been varied in this study: rotational speed (RS), plunge depth (PD) and dwell time (DT). DT refers to the time in which sleeve and pin rotate without vertical displacement to allow better material mixing. Weld strength has been characterized using lap shear testing on a screw-driven Zwick testing machine with a constant cross head speed of $2 \mathrm{~mm} / \mathrm{min}$ and at room temperature.

Several preliminary experiments were initially performed to find out feasible working limits of the FSpW parameters. The working range was decided upon by inspecting macrostructure and LSS. As shown in Table 1, each parameter was set up at three levels. Taguchi method was applied using Minitab software for designing the experiment. Since each three-level parameter has two degrees of freedom $(\mathrm{DF}=$ number of levels - 1), the total DF required is six. The DF of selected orthogonal array must be greater than or at least equal to the total DF, and hence an L9 array $(\mathrm{DF}=8)$ is suitable for the present study. LSS comprehends the quality characteristic.

Table 1. Welding parameters and their levels.

\begin{tabular}{c|c|c|c|c}
\hline Parameter & Symbol & Level 1 & Level 2 & Level 3 \\
\hline $\begin{array}{c}\text { Rotational speed } \\
\text { (rpm) }\end{array}$ & RS & 2000 & 2500 & 3000 \\
\hline $\begin{array}{c}\text { Plunge depth } \\
\text { (mm) }\end{array}$ & PD & 2.3 & 2.7 & 3.0 \\
\hline Dwell time (s) & DT & 0 & 1.5 & 3 \\
\hline
\end{tabular}


Table 2. L9 orthogonal array with response, mean and $\mathrm{S} / \mathrm{N}$ ratio.

\begin{tabular}{|c|c|c|c|c|c|c|c|c|}
\hline \multirow{2}{*}{ Condition } & \multicolumn{3}{|c|}{ Parameter } & \multicolumn{3}{|c|}{ Response } & \multirow{2}{*}{ Mean LSS (kN) } & \multirow{2}{*}{$\mathrm{S} / \mathrm{N}$ ratio $(\mathrm{dB})$} \\
\hline & $\mathrm{RS}$ (rpm) & $\mathrm{PD}(\mathrm{mm})$ & DT (s) & $\mathrm{LSS}_{1}(\mathrm{kN})$ & $\mathrm{LSS}_{2}(\mathrm{kN})$ & $\mathrm{LSS}_{3}(\mathrm{kN})$ & & \\
\hline 1 & 2000 & 2.3 & 0 & 3.10 & 3.18 & 3.04 & 3.11 & 9.8415 \\
\hline 2 & 2000 & 2.7 & 1.5 & 4.36 & 4.34 & 4.37 & 4.36 & 12.7830 \\
\hline 3 & 2000 & 3.0 & 3 & 4.77 & 4.56 & 4.51 & 4.61 & 13.2727 \\
\hline 4 & 2500 & 2.7 & 0 & 4.82 & 4.59 & 4.51 & 4.64 & 13.3201 \\
\hline 5 & 2500 & 3.0 & 1.5 & 4.79 & 4.55 & 4.50 & 4.61 & 13.2707 \\
\hline 6 & 2500 & 2.3 & 3 & 4.29 & 4.02 & 4.01 & 4.11 & 12.2572 \\
\hline 7 & 3000 & 3.0 & 0 & 4.56 & 4.71 & 4.94 & 4.74 & 13.4954 \\
\hline 8 & 3000 & 2.3 & 1.5 & 4.07 & 4.24 & 4.15 & 4.15 & 12.3643 \\
\hline 9 & 3000 & 2.7 & 3 & 4.28 & 4.28 & 4.57 & 4.38 & 12.8105 \\
\hline
\end{tabular}

Table 3. Main effects of LSS (mean and S/N ratio).

\begin{tabular}{c|c|c|c|c|c|c}
\hline \multirow{2}{*}{ Level } & \multicolumn{3}{|c|}{ Mean LSS $(\mathrm{kN})$} & \multicolumn{3}{c}{ S/N ratio (dB) } \\
\cline { 2 - 7 } & RS & PD & DT & RS & PD & DT \\
\hline 1 & 4.026 & 3.789 & 4.161 & 11.970 & 11.490 & 12.220 \\
\hline 2 & 4.453 & 4.458 & 4.374 & 12.950 & 12.970 & 12.810 \\
\hline 3 & 4.422 & 4.654 & 4.366 & 12.890 & 13.350 & 12.780 \\
\hline Delta & 0.428 & 0.866 & 0.213 & 0.980 & 1.860 & 0.590 \\
\hline Rank & 2 & 1 & 3 & 2 & 1 & 3 \\
\hline
\end{tabular}

Table 4. ANOVA results for mean of LSS.

\begin{tabular}{c|c|c|c|c|c}
\hline \multirow{2}{*}{ Source } & \multicolumn{5}{|c}{ Mean LSS } \\
\cline { 2 - 6 } & DF & SS & MS & F & P\% \\
\hline RS & 2 & 0.3413 & 0.1707 & 1.03 & 17.11 \\
\hline PD & 2 & 1.2353 & 0.6176 & 3.74 & 61.93 \\
\hline DT & 2 & 0.0874 & 0.0437 & 0.26 & 4.38 \\
\hline Error & 2 & 0.3307 & 0.1653 & - & 16.58 \\
\hline Total & 8 & 1.9947 & - & - & 100.00 \\
\hline
\end{tabular}

$D F=$ degrees of freedom, $S S=$ sum of squares, $M S=$ mean square, $F=F$-test and $P \%=$ percentage of contribution.

Table 5. ANOVA results for S/N ratio of LSS.

\begin{tabular}{c|c|c|c|c|c}
\hline \multirow{2}{*}{ Source } & \multicolumn{5}{|c}{ S/N ratio } \\
\cline { 2 - 6 } & DF & SS & MS & F & P\% \\
\hline RS & 2 & 1.8255 & 0.9127 & 1.01 & 18.10 \\
\hline PD & 2 & 5.7961 & 2.8980 & 3.22 & 57.48 \\
\hline DT & 2 & 0.6601 & 0.3300 & 0.37 & 6.55 \\
\hline Error & 2 & 1.8014 & 0.9007 & - & 17.87 \\
\hline Total & 8 & 10.0830 & - & - & 100.00 \\
\hline
\end{tabular}

$D F=$ degrees of freedom, $S S=$ sum of squares, $M S=$ mean square, $F=F$-test and $P \%=$ percentage of contribution. 


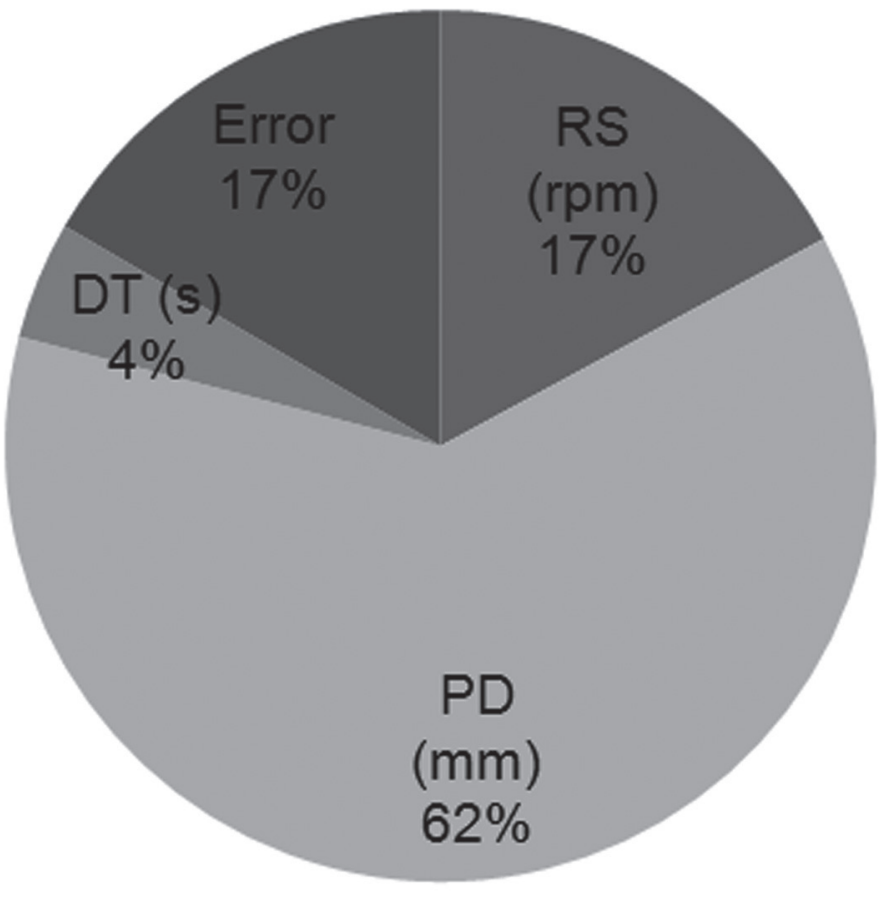

(a)

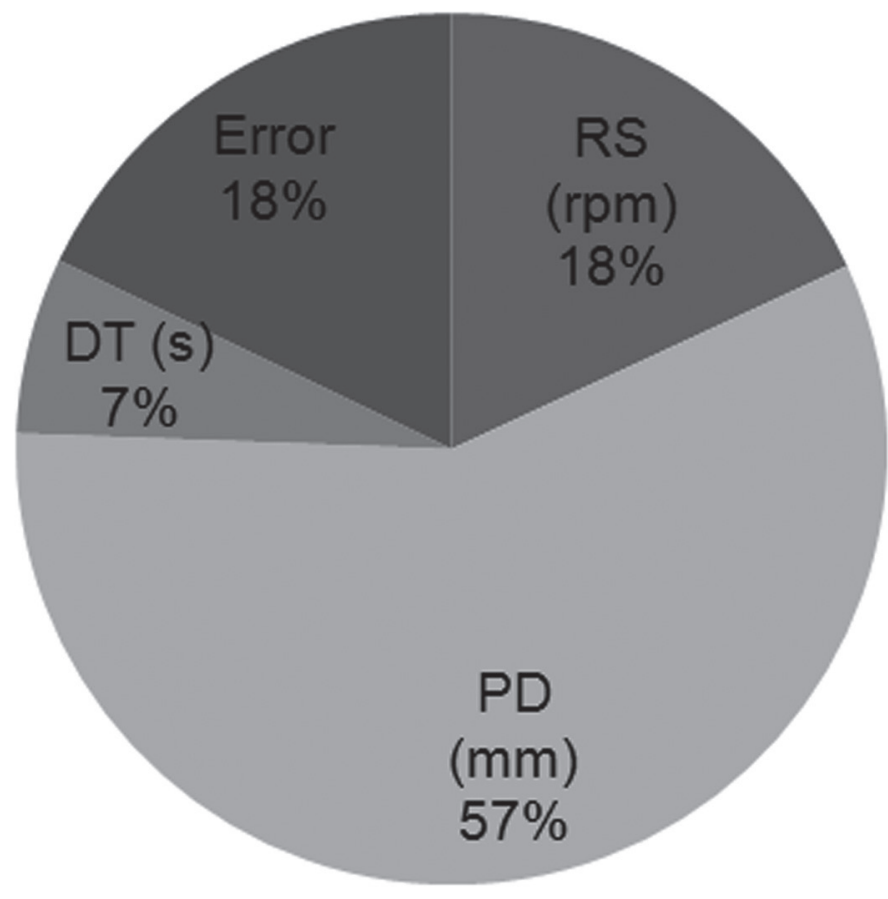

(b)

Figure 2. Contribution of each parameter on (a) mean LSS and (b) S/N ratio.

\section{Results and Discussion}

LSS experimental values are presented in Table 2 along with the calculated mean (average) and $\mathrm{S} / \mathrm{N}$ ratio for each combination of parameters. $\mathrm{S} / \mathrm{N}$ ratio is used in Taguchi method to measure the deviation of the quality characteristics from the desired value. Since it is desired to maximize the response, the $\mathrm{S} / \mathrm{N}$ ratio was chosen according to the category of "larger-thebetter". Table 3 gives mean LSS and S/N ratio calculated for each parameter at all three levels. The mean response states the average value of the performance characteristic for each parameter at different levels. The mean of one level is calculated as the average of all responses obtained in that particular level.

The values updated in the last two rows of Table 3 are delta value and rank, which help assessing which parameter has the greatest effect on the response. By taking the difference between the highest and the lowest average for a parameter, delta measures the size of the effect. Considering the calculated delta values, rank orders the parameters from the greatest to the least effect on the response with numbers from 1 to 3 respectively. The greatest variation of both mean and $\mathrm{S} / \mathrm{N}$ ratio was observed for PD, revealing that this parameter has the most important effect on LSS. RS has a lower relevant effect and DT shows the lowest effect of all parameters.

ANOVA was carried out to establish the relative importance of parameters in terms of variance and percentage of contribution $(\mathrm{P} \%)$ on LSS. Tables 4 and 5 show the ANOVA results of mean and $\mathrm{S} / \mathrm{N}$ ratio, respectively. F-test is based on comparing model and residual variances through the ratio between the model mean square and the residual or error mean square. F-value is close to one when the variance values are similar, which means a low effect of the parameter on the response, whereas high $\mathrm{F}$-value indicates a significant effect [5]. $\mathrm{P} \%$ is a function of sum of squares and indicates the relative power of each parameter to reduce the total variation [6,7]. Figure 2 shows the contribution of the parameters.

In summary, LSS is significantly affected by PD, followed by RS with a lower effect, both in terms of mean and $\mathrm{S} / \mathrm{N}$ ratio. It suggests that PD is a key parameter to control LSS, which is in agreement with the achievements from main effects (Table 3 ). In the case of DT, the F-value below unity indicates that this parameter does not take great effect on LSS, as evidenced by the low contribution on LSS.

Figure 3 presents the main effects plots for mean LSS and $\mathrm{S} / \mathrm{N}$ ratio. The flatness profile of DT curve also indicates the reduced contribution of this parameter on LSS, while the importance of PD is once more confirmed by the steep profile of its curve. In the investigated range, PD plot suggests an increase in this parameter to obtain better joints, while RS and DT plots indicate a slight reduction in the weld quality above the intermediate levels. As reported for FSSW process [10], it is possible that the heat input has a strong and direct correlation with mechanical performance of the weld. Clearly more heat is generated by friction when the parameters are individually increased. When the heat efficiency is high, the reduction in the viscosity of plasticized material leads to a decrease in torque and hence in the heat input. 


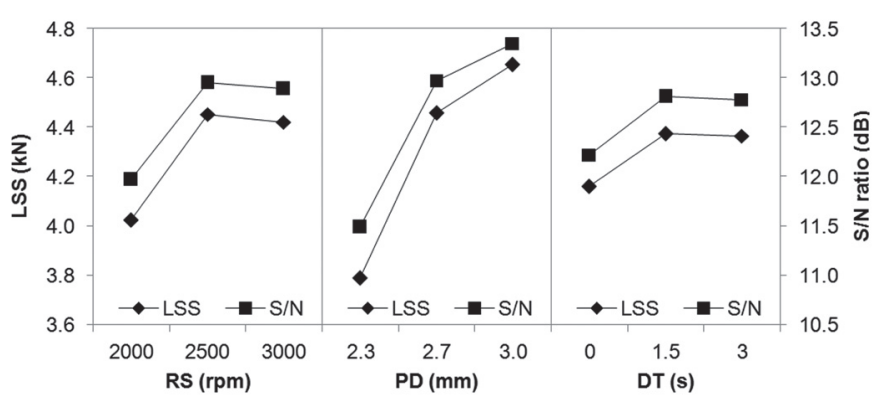

Figure 3. Main effects plots for mean LSS and S/N ratio.

Since larger $\mathrm{S} / \mathrm{N}$ values correspond to better quality characteristic with minimum variance, the purpose of DOE is to determine not only the maximum mean LSS but also the highest possible $\mathrm{S} / \mathrm{N}$ ratio. Along with Table 3, Figure 3 states that the highest value of LSS is achieved at the high level of PD and the medium levels of both RS and DT. Hence, Taguchi method suggests that the best settings to optimize LSS comprise RS of $2500 \mathrm{rpm}, \mathrm{PD}$ of $3.0 \mathrm{~mm}$ and DT of 1.5 seconds. Note that this combination of parameters is already included in the L9 orthogonal array (condition 5 in Table 2). Since orthogonal arrays do not test all possible combinations of parameters, interaction effect was not included in the optimization process.

A careful analysis of Table 2 indicates other combinations of parameters that provide LSS values as high as the value provided by condition 5 , such as conditions 3,4 and 7 . Figure 4 presents the standard deviation for all combinations of parameters, which varies from 0.02 (for condition 2) to 0.19 (for condition 7). There are no substantial differences in the LSS results of the four conditions previously mentioned, suggesting similar heat input in such cases.

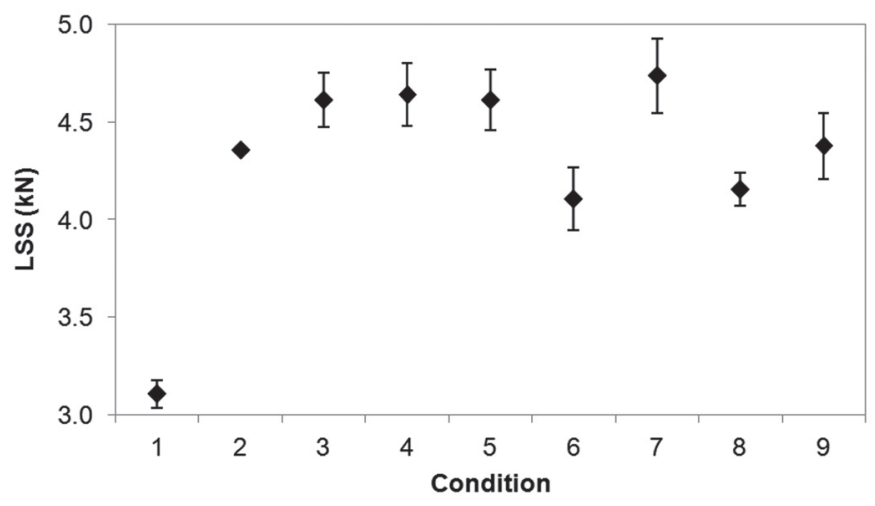

Figure 4. Mean and standard deviation plots for LSS.

Although there is not a standard way of obtaining the stress of the spot joint from the load, the lap shear stress (LSSt) is defined as the ratio between LSS and the circular area of the joint (considering the outer diameter of the tool component). This type of procedure is commonly adopted in cases where the real welding area is not measurable. In this study, LSS varies from about 3.1 to $4.7 \mathrm{kN}$, which results in a variation of LSSt between 48.9 and $74.5 \mathrm{MPa}$. The LSSt value obtained from the welds produced by FSSW is about $41 \mathrm{MPa}$ in a 1.3 $\mathrm{mm}$ thick specimen with removal of surface oxide to enhance the partially metallurgical bonding [11]. This result is inferior when compared with all the results (except for condition 1) obtained through FSpW, which indicates the possibility of direct replacement of the FSSW technique.

\section{Conclusions}

The effect of friction spot welding parameters on lap shear strength of AZ31 alloy was investigated by Taguchi method. Tool plunge depth was found to have the greatest influence on both mean and $\mathrm{S} / \mathrm{N}$ ratio (around $60 \%$ of contribution), followed by rotational speed and dwell time. The determination of the optimum condition of parameters was not clear. The optimum combination suggested by Taguchi method was found to be 2500 $\mathrm{rpm}$ of rotational speed, $3.0 \mathrm{~mm}$ of plunge depth and 1.5 seconds of dwell time. However, standard deviation values indicated that other conditions of parameters provided similar strength. In the investigated range, friction spot welding technology showed a great potential over friction stir spot welding.

\section{Acknowledgments}

The authors would like to acknowledge the financial support provided by CNPq (National Council for Scientific and Technological Development) and FAPESP (Sao Paulo Research Foundation), Brazil. Authors are also grateful to Dr. Sergio Amancio for his assistance in the statistical field.

\section{References}

[1] SCHILlinG, C.; DOS SANTOS, J. Method and Device for Linking at Least Two Adjoining Work Pieces by Friction Welding. US Patent No. 6,722,556 B2. April 20, 2004

[2] DA SILVA, A.M. et al. Friction Spot and Friction Stir Spot Welding Processes - A Literature Review. Bulletin of National R\&D Institute for Welding and Material Testing, v. 3, p. 36-44, 2007.

[3] MONTGOMERY, D.C. Design and Analysis of Experiments. $4^{\text {th }}$ Edition. NY: John-Wiley \& Sons, Inc, 2006.

[4] ROSS, P.J. Taguchi Techniques for Quality Engineering. NY: Tata McGraw Hill, 1988.

[5] XIANSHENG, N. et al. The use of Taguchi method to optimize the laser welding of sealing neuro-stimulator. Optics and Lasers in Engineering, v. 48, n. 3, p. 297-304, 2011.

[6] LAKSHMINARAYANAN, A.K.; BALASUBRAMANIAN, V. Process parameters optimization for friction stir welding of RDE-40 aluminum alloy using Taguchi technique. Transactions of Nonferrous Metals Society of China, v. 18, n. 3, p. 548-554, 2008.

[7] JAYARAMAN, M. et al. Optimization of process parameters for friction stir welding of cast aluminum alloy A319 by Taguchi method. Journal of Scientific \& Industrial Research, v. 68, n. 1, p. 36-43, 2009.

[8] HUNT, F.; BADARINARAYAN, H.; OKAMOTO, K. Design of Experiments for Friction Stir Stitch Welding of Aluminum 
Alloy 6022-T4. SAE International, 2006-01-0970, 2006.

[9] BILICI, M.K.; YÜKLER, A.İ.; KURTULMUŞ, M. The Optimization of welding parameters for friction stir spot welding of high density polyethylene sheets. Materials and Design, v. 32, n. 7, p. 4074-4079, 2011.

[10] SU, P. et al. Energy Generation and Stir Zone Dimensions in Friction Stir Spot Welds. SAE International, 2006-01-0971, 2006.

[11] YANG, Q. et al. Microstructure and Mechanical Properties of Friction Stir Spot Welded AZ31 Mg Alloy. In: 7th International Friction Stir Welding Symposium, 2008. 